\title{
Macular function and structure in patients with center-involved diabetic macular edema before and after micropulse laser therapy
}

\author{
Barbara Nowacka' ${ }^{1}$ Katarzyna Mozolewska-Piotrowska ${ }^{2}$, Wojciech Lubiński ${ }^{1}$, Anna Machalińskaa ${ }^{2}$, Aleksandra Grabowicz \\ 'Second Department of Ophthalmology of the Pomeranian Medical University, Szczecin, Poland \\ ${ }^{2}$ First Department of Ophthalmology of the Pomeranian Medical University, Szczecin, Poland
}

\begin{abstract}
Aim of the study: To evaluate macular function and structure in patients with center-involved diabetic macular edema before and after micropulse laser therapy.

Material and methods: Twenty one eyes of 18 patients with centerinvolved diabetic macular edema (DME) in type 2 diabetes mellitus were treated twice with micropulse laser therapy at the baseline and 3 months after. At the baseline, 6th week, 3rd month and 6th month the following examinations were performed: distance best corrected visual acuity (log MAR), slit lamp examination of the anterior and posterior segment of the eye (Volk 90D lens), assessment of the macular thickness (OCT), as well as evaluation of the macular function (mfERG).
\end{abstract}

Results: Six weeks, 3 and 6 months after micropulse laser therapy (MPLT) no statistically significant change of distance best corrected visual acuity, bioelectrical function of bipolar cells and cones, or macular thickness in the fovea and parafoveal region were observed $(p>0.05)$.

Conclusions: Our study results suggest that usefulness of MPLT in treatment of center-involved DME seems to be limited, but it may have role in stabilization of visual function and macular structure. KEY WORDS: diabetic macular edema, OCT, micropulse laser therapy, mfERG.

\section{INTRODUCTION}

Diabetic retinopathy is a microangiopathy which leads to abnormal macular structure and damage of photoreceptors as a consequence of leakage from microaneurysms and damaged blood vessels and accumulation of fluid in the extracellular space of the outer and inner nuclear layer of the retina. The most common vision-threatening complication of diabetic retinopathy is diabetic macular edema (DME) [1-3], which may affect as many as one fourth of diabetic eyes [4]. The results of statistical analyses suggest that the number of diabetic patients increases each year. Therefore DME may become a significant public health problem, especially in developed countries, where diabetes usually affects working-age patients. The treatment options for DME include focal and grid laser photocoagulation, intravitreal steroids or anti-VEGF injections, and vitrectomy. At present anti-VEGF injections are the gold standard treatment for clinically significant DME, but recently a new treatment option for mild to moderate DME has appeared - micropulse laser therapy (MPLT). Study results have shown that MPLT increases or stabilizes visual acuity and reduces macular thickness without creating clinically visible retinal damage due to reduced laser exposure duration [5-7]. It is known that MPLT targets the retinal pigment epithelium (RPE), but the exact mechanism of its action is still not completely understood. It could be promotion of changes in the expression of cytokines $[8,9]$, repair of the inner blood retinal barrier [10], activation of heat shock protein and mitochondrial respiratory chain, and initiation of cellular signaling [1113], leading to repair and improvement of RPE function. Most studies evaluate the effectiveness of MPLT with the aid of visual acuity (VA), which indirectly provides information about foveal function, and optical coherence tomography (OCT), which reveals only structural changes of the macula. To ensure comprehensive and objective information about macular function in the course of DME treatment, the multifocal electroretinogram (mfERG) may be applied. It evaluates the function of bipolar cells and cone photoreceptors (the middle and outer layers of the retina) from the central 50-60 degree field of vision with the possibility of isolation 
of foveal and parafoveal function. Visual acuity corresponds to only 1 degree field of vision, and as a subjective method of assessing macular function it may vary depending on blood glucose levels [14]. Therefore, we decided to perform multifocal electroretinogram (mfERG), additionally to VA and OCT for macular function evaluation before and after MPLT. In the PubMed database we have found only 1 study describing mfERG recordings in DME eyes treated with MPLT [15], and its results showed no statistically significant improvement of mean values of P1 implicit times. The aim of the present study was to provide additional information about MPLT effectiveness.

\section{MATERIAL AND METHODS}

Twenty-one eyes of 18 patients ( 11 males, 7 females) aged $60.8 \pm 7.7$ years with center-involving DME of non-proliferative diabetic retinopathy in type 2 diabetes mellitus were treated twice with micropulse laser therapy - at the baseline and 3 months after. Inclusion criteria were as follows: age above 18 years, distance best corrected visual acuity (DBCVA) $\log M A R$ in range $0.7-0.0, \mathrm{HbA}_{1 \mathrm{c}}$ level below $8 \mathrm{mg} \%$, diabetic diffuse macular edema with central foveal involvement in the OCT, central retinal thickness less than $400 \mu \mathrm{m}$, deterioration of visual acuity due to DME with no other apparent cause, anti-VEGF intravitreal therapy has been postponed for at least 6 months. Exclusion criteria were as follows: proliferative retinopathy, uncontrolled hypertension, previous focal/grid laser treatment in macular region, intraocular injection of steroid or anti-VEGF within 3 months. The micropulse laser therapy (MPLT) was performed with a yellow SUPRA 577 laser, operating mode 5\% and power according to titration, but not exceeding $350 \mathrm{~mW}$. The scope of laser therapy covered the entire area of retinal edema with a small margin of retina adjacent to the edema (the number of impacts ranged between 400 to 975). Before the first MPLT, after 6 weeks, as well as 3 and 6 months, the following examinations were performed: assessment of DBCVA (ETDRS, log MAR), slit lamp examination of the anterior and posterior segment of the eye (Volk 90D lens), assessment of macular thickness (Spectralis OCT, Heidelberg Engineering), as well as evaluation of the macular function - mfERG (Roland Consult). All mfERG parameters were consistent with the current International Society for Clinical Electrophysiology of Vision (ISCEV) Standards with the exception of $60^{\circ}$ instead of $50^{\circ}$ field of vision stimulation [16].

\section{MULTIFOCAL ELECTRORETINOGRAM}

The examination was performed after maximal dilation (> $6 \mathrm{~mm}$ ) of the pupil with $10 \%$ phenylephrine. The active DTL thread electrode was positioned in contact with the cornea, the reference gold disc electrode was placed on the skin near the ipsilateral outer canthus and the ground gold disc electrode was placed on the forehead at Fpz. During the examination, monocular stimulation, central fixation and appropriate optical correction for a distance of $30 \mathrm{~cm}$ from the surface of the stimulating monitor were used. The stimulus and system parameters were as follows: a black and white matrix of 103 scaled hexagons displayed in the $60^{\circ}$ field of vision, luminance for white elements of $100 \mathrm{~cd} / \mathrm{m}^{2}$, the contrast between black and white hexagons of $97 \%$, amplifiers sensitivity of $20 \mu \mathrm{V} / \mathrm{div}$, filters of $10-300 \mathrm{~Hz}$, notch filters off, plots time of $83 \mathrm{~ms}$, artifact reject threshold of $8 \%$ (for the amplifiers range $\pm 100 \mu \mathrm{V}$ ), electrode impedance below $5 \mathrm{k} \Omega$. Six cycles were averaged off-line including digital smoothing $(2 \times)$, software reduction of line interference and manual correction, if necessary, applied to the automatic cursor placement. The analysis included response density and peak time of the P1-wave in ring 1 (R1) and ring 2 (R2), which correspond to the foveal and parafoveal retinal area, respectively. The mfERG stimuli location and anatomic area of R1 (0.0-2.3 $\left.{ }^{\circ}\right)$ corresponded roughly to the fovea and of R2 $\left(2.3-7.4^{\circ}\right)$ to the parafovea and partially to the perifovea.

Informed written consent was given by all subjects participating in this study. The Ethics Committee of the Pomeranian Medical University approved the project.

The Shapiro-Wilk test was used to evaluate the normality of distribution of analyzed parameters. Changes in parameter values at four time points (baseline, 6 weeks, 3 months and 6 months) were analyzed using the ANOVA test in the case of normal distribution, or the Friedman ANOVA test in the absence of normal distribution. The $p$-value $<0.05$ was considered as significant. The comparison of parameters between the two subgroups (central foveal thickness [CFT] above $300 \mu \mathrm{m}$ and below $300 \mu \mathrm{m}$ ) was performed using Student's t-test for the normal or the Mann-Whitney $U$ test for non-normally distributed data. The results were considered statistically significant at $p<0.05$. Data are presented as mean \pm standard deviation (SD).

\section{RESULTS}

\section{Distance best corrected visual acuity}

The mean DBCVA at the baseline was $0.17 \pm 0.18$ ( $\log$ MAR scale) and did not improve significantly after 6 weeks $(0.15 \pm 0.18)$ or after 3 months $(0.18 \pm 0.19)$ or 6 months $(0.14$ $\pm 0.18)$ of follow-up $(p=0.124)$. The results of DBCVA examinations are presented in Figure 1.

\section{Optical coherence tomography}

There was no statistically significant reduction of foveal and parafoveal thickness during the observation period. At the baseline mean CFT in OCT was $320.6 \pm 65.8 \mu \mathrm{m}$ and slightly increased to $327.4 \pm 70.3 \mu \mathrm{m}$ at 6 weeks and then to $345.5 \pm 79.9 \mu \mathrm{m}$ in the $3^{\text {rd }}$ month. At the $6^{\text {th }}$ month and after the second micropulse laser therapy CFT slightly decreased compared to the $3^{\text {rd }}$ month but the result $(328.6 \pm 94.7 \mu \mathrm{m})$ still remained statistically insignificant in comparison to all previous results $(p=0.578)$. The results of the parafoveal thickness were changing similarly to CFT - the baseline: $366.5 \pm 30.0 \mu \mathrm{m}, 6^{\text {th }}$ week: $370.3 \pm 34.3 \mu \mathrm{m}, 3^{\text {rd }}$ month: 372.0 $\pm 34.3 \mu \mathrm{m}, 6^{\text {th }}$ month: $364.2 \pm 44.4 \mu \mathrm{m}(p=0.377)$. The results of foveal and parafoveal thickness during 6-month follow-up are presented in Figure 2. 


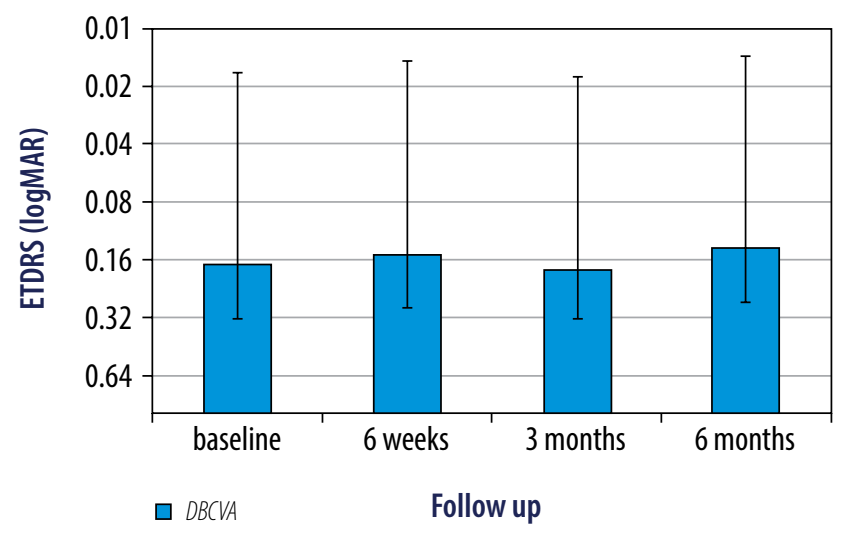

Figure 1. The results of DBCVA in center-involving DME treated with MLPT during 6 month follow-up. All results are statistically insignificant $(p>0.05)$ in comparison to the baseline and previous follow up examination

\section{Multifocal electroretinogram}

At the baseline the mean P1-response density in R1 was $46.2 \pm 28.4 \mathrm{nV} / \mathrm{deg}^{2}$, which was below our laboratory normal values (62.27-130.89 $\mathrm{nV} / \mathrm{deg}^{2}$ ). During the follow-up P1 did not differ statistically significantly and had the following values: $6^{\text {th }}$ week: $43.9 \pm 21.1 \mathrm{nV} / \mathrm{deg}^{2}, 3^{\text {rd }}$ month: 49.3 $\pm 28.4 \mathrm{nV} / \mathrm{deg}^{2}, 6^{\text {th }}$ month: $40.1 \pm 25.5 \mathrm{nV} / \mathrm{deg}^{2}(p=0.442)$. The mean P1-response density in R2 at the baseline was 20.0 $\pm 11.4 \mathrm{nV} / \mathrm{deg}^{2}$, which was also below our laboratory norms (32.01-72.24 nV/ $\mathrm{deg}^{2}$ ), and like the P1-response density in $\mathrm{R} 1$ it did not change statistically significantly during the follow-up period ( $6^{\text {th }}$ week: $25.9 \pm 12.2 \mathrm{nV} / \mathrm{deg}^{2}, 3^{\text {rd }}$ month: 22.6 $\pm 11.7 \mathrm{nV} / \mathrm{deg}^{2}, 6^{\text {th }}$ month: $\left.25.5 \pm 10.4 \mathrm{nV} / \mathrm{deg}^{2}, p=0.146\right)$. The mean P1 implicit time in R1 and R2 was within normal limits of our laboratory (R1 36.8-46.38 ms; R2 31.75-40.94 ms) and also remained stable during the whole follow-up period as follows: R1 baseline: $44.0 \pm 3.9 \mathrm{~ms}, 6^{\text {th }}$ week: $43.7 \pm 5.9 \mathrm{~ms}, 3^{\text {rd }}$ month: $43.5 \pm 4.7 \mathrm{~ms}$, $6^{\text {th }}$ month: $44.5 \pm 6.0 \mathrm{~ms}(p=0.972)$; R2 baseline: $39.8 \pm 4.1 \mathrm{~ms}, 6^{\text {th }}$ week: $38.9 \pm 2.7 \mathrm{~ms}, 3^{\text {rd }}$ month: 40.0 $\pm 4.5 \mathrm{~ms}, 6^{\text {th }}$ month: $39.1 \pm 5.4 \mathrm{~ms}(p=0.996)$. However, even though the mean P1 implicit time in R1 and R2 was normal, in some patients $\mathrm{P} 1$ implicit time was visibly delayed at the baseline and during follow-up, indicating persistent dysfunction of the cone system in the macular region. The results of the mfERG are summarized in Figures 3 and 4 . An example of a diabetic patient's eye treated with MPLT during 6-month follow-up is shown in Figure 5.

Based on the result of Citirik et al. [17] that patients with initial macular thickness of $300 \mu \mathrm{m}$ or less respond better to MPLT, patients in our study were divided into two groups upon their initial CFT. Group 1 was composed of patients with CFT below $300 \mu \mathrm{m}$ (8 eyes), while Group 2 was composed of patients with CFT $\geq 300 \mu \mathrm{m}$ (13 eyes). It was not observed that either of groups achieved a greater reduction in macular thickness (OCT) or a more pronounced improvement in function (VA, mfERG). The results of this comparison are summarized in Table I.

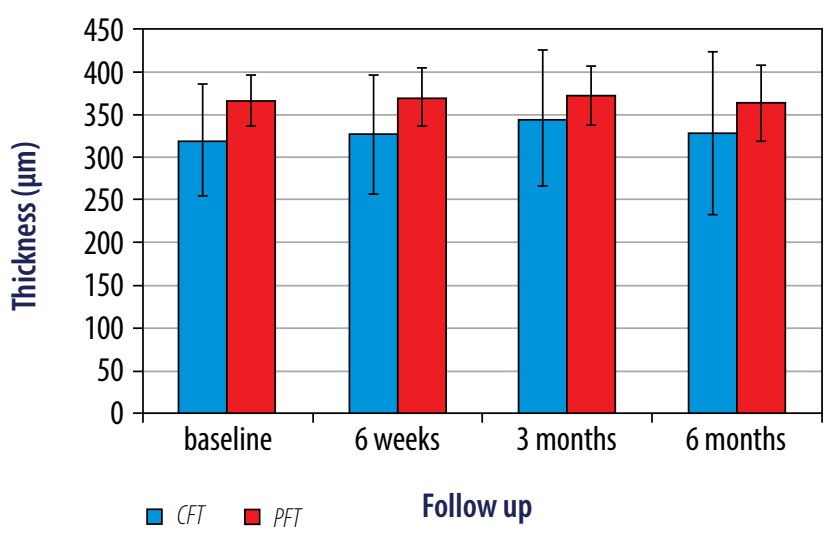

Figure 2. The results of foveal (CFT) and parafoveal (PFT) thickness in centerinvolving DME treated with MLPT during 6 month follow-up. All results are statistically insignificant $(p>0.05)$ in comparison to the baseline and previous follow up examination

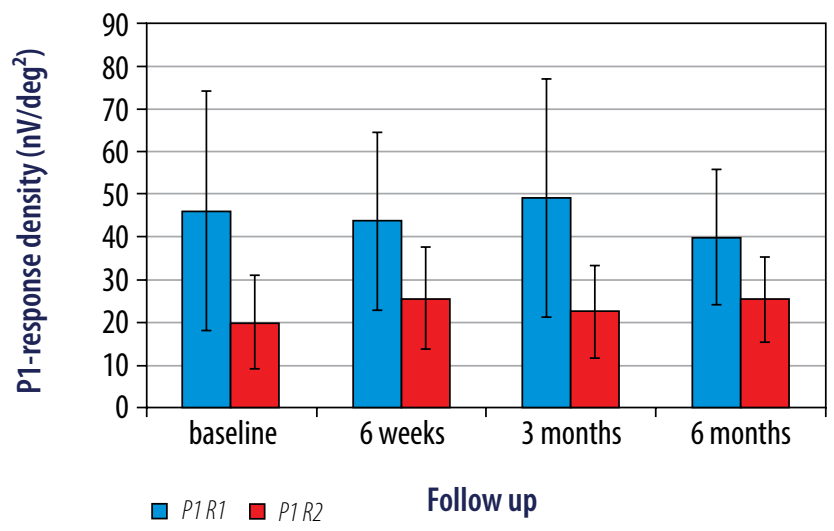

Figure 3. The results of the mean mfERG P1-response density in $R 1$ and $R 2$ in center-involving DME treated with MLPT during 6 month follow-up. All results are statistically insignificant $(p>0.05)$ in comparison to the baseline and previous follow up examination

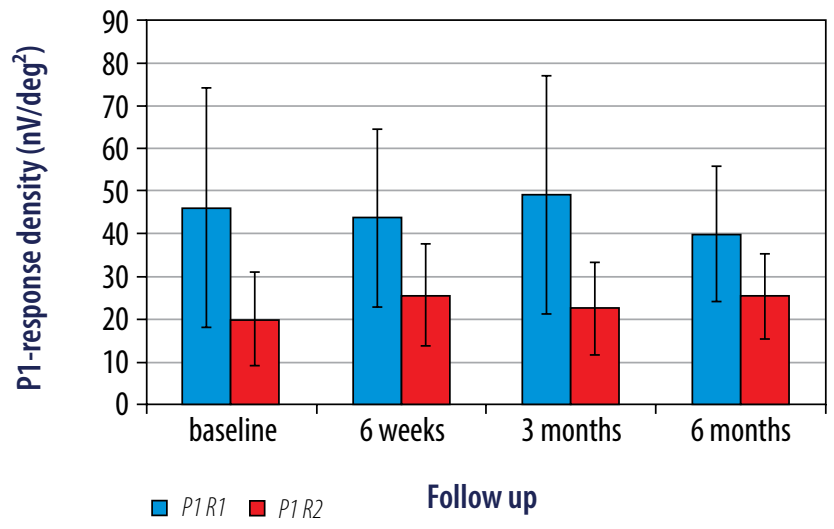

Figure 4. The results of the mean mfERG P1-implicit time in $\mathrm{R} 1$ and $\mathrm{R} 2$ in center-involving DME treated with MLPT during 6 month follow-up. All results are statistically insignificant $(p>0.05)$ in comparison to the baseline and previous follow up examination 

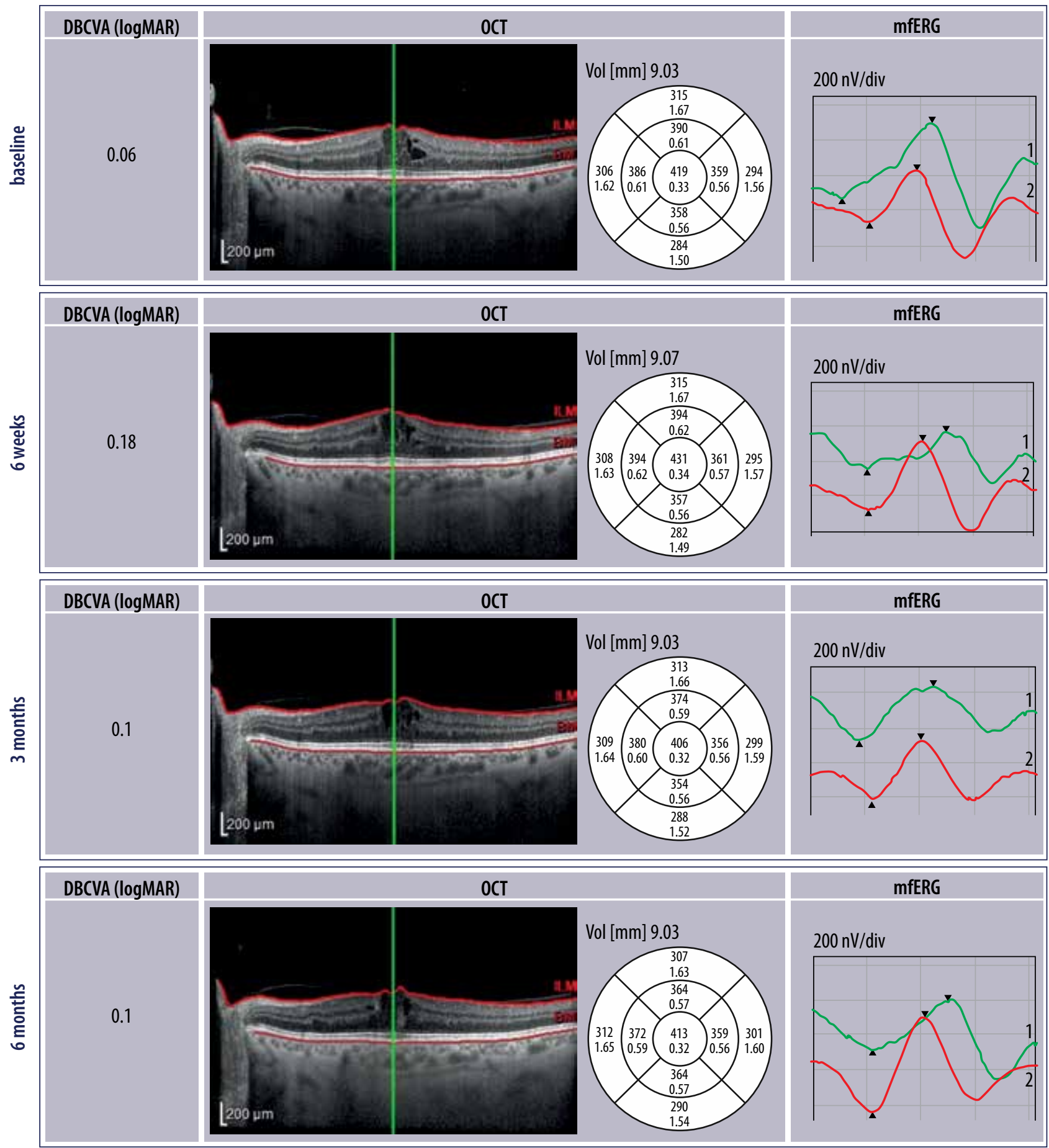

Figure 5. The example of diabetic patient's eye treated with MPLT during 6-month follow up - the stable foveal structure (OCT) and function (mfERG) are visable

Table I. Comparison of changes of the mean (FT, PFT, VA and P1-response density in groups obtained at the basis of initial CFT $\leq 300 \mu \mathrm{m}$ (Group 1) and > $300 \mu \mathrm{m}$ (Group 2)

\begin{tabular}{|c|c|c|c|c|c|c|c|c|c|c|c|c|c|c|c|c|c|c|c|c|}
\hline & \multicolumn{5}{|c|}{ Baseline } & \multicolumn{5}{|c|}{6 weeks } & \multicolumn{5}{|c|}{3 months } & \multicolumn{5}{|c|}{6 months } \\
\hline & $\begin{array}{c}\text { CFT } \\
(\mu \mathrm{m})\end{array}$ & $\begin{array}{l}\text { PFT } \\
(\mu \mathrm{m})\end{array}$ & $\begin{array}{c}\text { VA } \\
\text { (logMAR) }\end{array}$ & $\begin{array}{l}\text { P1 R1 } \\
(\mu \mathrm{V})\end{array}$ & $\begin{array}{c}\text { P1 R2 } \\
(\mu \mathrm{V})\end{array}$ & $\Delta C F T$ & $\triangle \mathrm{PFT}$ & $\Delta V A$ & $\begin{array}{l}\Delta \mathrm{P} 1 \\
\mathrm{R} 1\end{array}$ & $\begin{array}{l}\Delta P 1 \\
\text { R2 }\end{array}$ & $\triangle \mathrm{CCF}$ & $\triangle \mathrm{PFT}$ & $\Delta V A$ & $\begin{array}{l}\Delta \mathrm{P} 1 \\
\mathrm{R} 1\end{array}$ & $\begin{array}{c}\Delta \mathrm{P} 1 \\
\mathrm{R} 2\end{array}$ & $\Delta \mathrm{CFT}$ & $\triangle \mathrm{PFT}$ & $\Delta V A$ & $\begin{array}{l}\Delta \mathrm{P} 1 \\
\mathrm{R} 1\end{array}$ & $\begin{array}{l}\Delta \mathrm{P} 1 \\
\mathrm{R} 2\end{array}$ \\
\hline $\begin{array}{l}\text { Group } 1 \\
\text { (8 eyes) }\end{array}$ & 265.0 & 347.6 & 0.22 & 31.4 & 16.7 & 22.7 & 4.5 & -0.01 & 7.0 & 9.7 & 15.9 & 5.9 & -0.02 & 5.5 & 3.9 & 3.9 & -10.6 & -0.05 & 5.1 & 10.0 \\
\hline $\begin{array}{l}\text { Group } 2 \\
\text { (12 eyes) }\end{array}$ & 360.3 & 378.1 & 0.14 & 55.7 & 22.2 & -5.4 & 3.4 & -0.02 & -8.3 & 3.4 & 19.7 & 5.4 & 0.03 & 1.2 & 1.5 & 6,3 & 3.4 & -0.02 & -13.5 & 1.9 \\
\hline
\end{tabular}

$\Delta$ - difference in comparison to the baseline; (FT - central retinal thickness; PFT - parafoveal macular thickness; P1 R1 - mfERG P1-response density in ring 1; P1 R2 - mfERG P1-response density in ring 2. All results obtained during the follow up were statistically insignificant $(p>0.05)$ 


\section{DISCUSSION}

In the present study, for the first time we provide objective data for stabilization of bioelectrical function of the retina treated with MPLT and also emphasize the positive role of this type of treatment in center-involved DME. The results of previous studies revealed that $577 \mathrm{~nm}$ MPLT is effective in stabilizing/increasing DBCVA and stabilizing/reducing retinal thickness in center-involving DME. Vujosevic et al. [18] investigated 26 eyes with center-involving DME and found stabilization of BCVA but a significant reduction of mean CFT from $357.8 \pm 46.1 \mu \mathrm{V}$ to $339.9 \pm 55.7 \mu \mathrm{V}(p=0.009)$ in 6-month follow-up. Similar results with respect to DBCVA and CFT were obtained by Masafumi et al. [19] and Inagaki et al. [20]. On the other hand, Kwon et al. [21] showed that MPLT significantly improved DBCVA, but not reduction of CFT. However, in the abovementioned study the analyzed end-point varied from 6 to 14 months and laser sessions differed between individuals. In a recent study, Citirik [17] stratified patients into four groups according to baseline CFT and observed statistically significant CFT reduction and visual gain at 2 months in patients with CFT of $300 \mu \mathrm{m}$ or less. Results from our patients obtained at 6-week follow-up revealed slight improvement of DBCVA in both groups and slight reduction of retinal thickness in the group with CFT $>300 \mu \mathrm{m}$, but not in the CFT $\leq 300 \mu \mathrm{m}$ group, which gained thickness. Moreover, at the $3^{\text {rd }}$ month follow-up there was a similar increase of CFT in both groups in comparison to the baseline, and the CFT $>300 \mu \mathrm{m}$ group lost the initial DBCVA improvement. However, all mentioned changes were statistically insignificant $(p>0.05)$. The mfERG results also revealed no improvement in MPLT patients. To date, we have found only one study in the literature [15] which has evaluated functional effects of MPLT with electrophysiological examinations. Although Venkatehs et al. [15] focused on comparison between MPLT and Nd:YAG laser treatment, it can be observed that mean P1 implicit time changed insignificantly from 46.27 $\pm 4.9 \mathrm{~ms}$ at the baseline to $44.57 \pm 2.9 \mathrm{~ms}$ at the $3^{\text {rd }}$ month and $45.27 \pm 3.4 \mathrm{~ms}$ at the $6^{\text {th }}$ month follow-up in MPLT patients $(p=0.23)$, which is consistent with our results.

There are limitations to our present study. Firstly, the number of patients in the study was relatively small, and some subjects had two eyes enrolled in the study while others had one. However, the same results are obtainable using 1 eye for each subject. Secondly, $\mathrm{HbA}_{1 \mathrm{c}}$ was determined only at the baseline. It is known that systemic regulation of diabetes mellitus may affect the treatment response to MPLT.

\section{CONCLUSIONS}

In conclusion, according to ETDRS Report Number 9 [22] the risk of moderate visual loss ( 15 or more letters logMAR) in diabetic patients with untreated DME is $3.8 \%$ in 4 months and $8.6 \%$ in 1 year. In the present study, after MPLT no deterioration of visual acuity of 15 or more letters was observed during 6 months of follow-up, and for the first time we reported stabilization of bioelectrical function of bipolar cells and cones. Therefore, the usefulness of MPLT in treatment of center-involved DME seems to be limited to stabilization of visual function and macular structure.

\section{DISCLOSURE}

The authors declare no conflict of interest.

\section{References}

1. Nicholson BP, Schachat AP. A review of clinical trials of anti-VEGF agents for diabetic retinopathy. Graefes Arch Clin Exp 0phthalmol 2010; 248: 915-30.

2. Klein R, Klein BE, Moss SE. Visual impairment in diabetes. Ophthalmology 1984; 91: 1-9.

3. Soheilian M, Garfami KH, Ramezani A, et al. Two-year results of a randomized trial of intravitreal bevacizumab alone or combined with triamcinolone versus laser in diabetic macular edema. Retina 2012; 32: 314-321.

4. Klein R, Klein BE, Moss SE, et al. The Wisconsin epidemiologic study of diabetic retinopathy. IV. Diabetic macular edema. Ophthalmology 1984; 91: 1464-1474.

5. Luttrull JK, Musch DC, Mainster MA. Subthreshold diode micropulse photocoagulation for the treatment of clinically significant diabetic macular oedema. Br J Ophthalmol 2005; 89: 74-80.

6. Figueira J, Khan J, Nunes S, et al. Prospective randomised controlled trial comparing sub-threshold micropulse diode laser photocoagulation and conventional green laser for clinically significant diabetic macular oedema. Br J Ophthalmol 2009; 93: 1341-1344.

7. Vujosevic S, Bottega E, Casciano M, et al. Microperimetry and fundus autofluorescence in diabetic macular edema: subthreshold micropulse diode laser versus modified early treatment diabetic retinopathy study laser photocoagulation. Retina 2010; 30: 908-916.

8. Luttrull JK, Dorin G. Subthreshold diode micropulse laser photocoagulation (SDM) as invisible retinal phototherapy for diabetic macular edema: a review. Curr Diabetes Rev 2012; 8: 274-284.

9. Bartsch DU, Weinreb RN, Zinser G, Freeman WR. Confocal scanning infrared laser ophthalmoscopy for indocyanine green angiography. Am J Ophthalmol 1995; 120: 642-51.

10. Bresnick GH. Diabetic maculopathy. A critical review highlighting diffuse macular edema. Ophthalmology 1983; 90: 1301-1317.

11. Holz FG, Bellmann C, Margaritidis M, et al. Patterns of increased in vivo fundus autofluorescence in the junctional zone of geographic atrophy of the retinal pigment epithelium associated with age-related macular degeneration. Graefes Arch Clin Exp Ophthalmol 1999; 237: 145-152.

12. ETDRS report number 10. Early Treatment Diabetic Retinopathy Study Research Group Grading diabetic retinopathy from stereoscopic color fundus photographs - an extension of the modified Airlie House classification. Ophthalmology 1991; 98: 786-806.

13. Ferris FL 3rd, Kassoff A, Bresnick GH, Bailey I. New visual acuity charts for clinical research. Am J Ophthalmol 1982; 94: 91-96.

14. Fledelius HC. Refractive changes in diabetes mellitus around onset or when poorly controlled. A clinical study. Acta Ophthalmol Scand 1987; 65: 53-57. 
15. Venkatesh P, Ramanjulu R, Azad R, et al. Subthreshold micropulse diode laser and double frequency neodymium: YAG laser in treatment of diabetic macular edema: a prospective, randomized study using multifocal electroretinography. Photomed Laser Surg 2011; 29: 727-733.

16. Hood DC, Bach M, Brigell M, et al. International Society For Clinical Electrophysiology of Vision. ISCEV standard for clinical multifocal electroretinography (mfERG) (2011 edition). Doc Ophthalmol 2012; 124: 1-13.

17. Citirik M. The impact of central foveal thickness on the efficacy of subthreshold micropulse yellow laser photocoagulation in diabetic macular edema. Lasers Med Sci 2019; 34: 907-912.

18. Vujosevic S, Martini F, Longhin E, et al. Subthreshold micropulse yellow laser versus subthreshold micropulse infrared laser in center -involving diabetic macular edema: Morphologic and Functional Safety. Retina 2015; 35: 1594-1603.

19. Hamada M, Ohkoshi K, Inagaki K, et al. Subthreshold Photocoagulation Using Endpoint Management in the PASCAL ${ }^{\circledR}$ System for Diffuse Diabetic Macular Edema. J Ophthalmol 2018; 2018: 7465794.

20. Inagaki K, Ohkoshi K, Ohde S, et al. Comparative efficacy of pure yellow (577-nm) and 810-nm subthreshold micropulse laser photocoagulation combined with yellow (561-577-nm) direct photocoagulation for diabetic macular edema. Jpn J Ophthalmol 2015; 59: 21-28.

21. Kwon YH, Lee DK, Kwon OW. The short-term efficacy of subthreshold Micropulse yellow (577-nm) laser photocoagulation for diabetic macular edema. Korean J Ophthalmol 2014; 28: 379-385.

22. Early Treatment Diabetic Retinopathy Study Research Group. Early photocoagulation for diabetic retinopathy. ETDRS report number 9. Ophthalmology 1991; 98: 766-785. 